\title{
Identification of polyphenolic compounds and determination of antioxidant activity in extracts and infusions of buckwheat leaves
}

\author{
Kinga Dziadek ${ }^{1}$ - Aneta Kopeć ${ }^{1}$ Ewa Piątkowska ${ }^{1}$ Teresa Leszczyńska ${ }^{1}$ • \\ Elżbieta Pisulewska $^{2}$. Robert Witkowicz ${ }^{2}$ Beata Bystrowska ${ }^{3} \cdot$ Renata Francik $^{4,5}$
}

Received: 11 April 2017 / Revised: 4 July 2017 / Accepted: 21 July 2017 / Published online: 2 August 2017

(C) The Author(s) 2017. This article is an open access publication

\begin{abstract}
The objective of this study was to determine the chemical composition in the dried leaves and the content of bioactive compounds, antioxidant activity as well as the identification of polyphenolic compounds not only in extracts but also in infusions prepared from leaves of selected strains of buckwheat. To the best of our knowledge, it is the first comprehensive and in-depth study, which focuses on identification and quantitative determination of individual polyphenolic compounds of buckwheat leaves. Furthermore, the aim of presented research is to analyse the new, unknown strains of buckwheat. A statistically significant effect of strain on the content of individual components was observed. The extracts contained more polyphenols and were characterized by higher antioxidant activity than infusions. Strains DW15 and DWO Karzel were characterized by one of the highest contents of polyphenols, dietary fibre, protein, ash and antioxidant activity. Phenolic acids (3,5diCQA, ferulic acid, sinapinic acid, $p$-coumaric acid), flavanones (hesperidin), flavonoids (isorhamnetin) as well as
\end{abstract}

Aneta Kopeć

akopec@ar.krakow.pl

1 Department of Human Nutrition, Faculty of Food Technology, University of Agriculture in Krakow, Balicka 122, 30-149 Kraków, Poland

2 Department of Crop Production, Faculty of Agriculture and Economics, University of Agriculture in Krakow, al. Mickiewicza 21, 31-120 Kraków, Poland

3 Department of Tox, Collegium Medicum, Jagiellonian University, Medyczna 9, 30-688 Kraków, Poland

4 Department of Bioorganic Chemistry, Medical College, Pharmacy Faculty, Jagiellonian University, Medyczna 9, 30-688 Kraków, Poland

5 Institute of Health, State Higher Vocational School, Staszica 1, 33-300 Nowy Sacz, Poland flavanols (catechin) and flavonols (rutin, quercetin) in the extracts and infusions, were found. Both extracts and infusions were the richest in ferulic acid. These studies indicate that the buckwheat leaves can be used for preparation of various types of tea and can also be introduced for consumers as the source of bioactive compounds.

Keywords Buckwheat · Leaves · Extract - Infusion · Polyphenols $\cdot$ Antioxidant activity $\cdot$ Ferulic acid

\section{Introduction}

Buckwheat (Fagopyrum esculentum Moench) is an annual plant, which is cultivated mainly for seeds. Buckwheat seeds can be recognized as an important food source, because they contain proteins with high biological value and balanced amino acid composition as well as bioactive compounds, mainly polyphenols $[1,2]$. Buckwheat seeds are used to produce groats, flour, pasta and bread [3, 4]. In China, leaves and flowers of buckwheat are also used in traditional medicine. Food producers utilize these parts of plant for tea production, which decreases cholesterol and glucose level in the blood. These properties are due to the high content of phenolic compounds and dietary fibre in the leaves of buckwheat [5]. Dietary fibre protects from hyperglycaemia, hypercholesterolaemia, obesity and some types of cancer, especially colon cancer [6].

Most studies focus on chemical composition of buckwheat seeds as well as healthy properties [7-10]. In the available literature there are little data concerning the other parts of buckwheat. Therefore, there is a need to examine other parts of buckwheat, such as leaves, in terms of their chemical composition, content of bioactive compounds and antioxidant activity. Thus, it is very important to examine 
these by-products because this knowledge can be used in the prevention and treatment of the chronic non-communicable diseases. It would be possible to create novel functional food products and to better use of the byproduct of buckwheat production.

The objective of this study was to determine the chemical composition in the dried leaves and the content of bioactive compounds, antioxidant activity in the leaves as well as the identification of polyphenolic compounds not only in extracts but also in infusions prepared from leaves of selected strains of buckwheat. To the best of our knowledge it is the first comprehensive and in-depth study which focuses on identification and quantitative determination of individual polyphenolic compounds of buckwheat leaves. Furthermore, the aim of presented research is to analyse the new, unknown strains of buckwheat.

\section{Materials and methods}

\section{Reagents}

All the solvents and standards were of analytical grade. Standards of 3,5-di-caffeoylquinic acid (3,5-diCQA), ferulic acid, 3,5-dimethoxy-4-hydroxycinnamic acid (sinapinic acid), $p$-coumaric acid, hesperidin, isorhamnetin, catechin, rutin, quercetin were purchased from Sigma-Aldrich (Saint Louis, MO, USA). All the stock solutions of standards, were prepared in methanol and were stored at $-20{ }^{\circ} \mathrm{C}$. Further dilutions were prepared using methanol. Chlorogenic acid, Folin-Ciocialteu reagent, $\mathrm{ABTS}^{++}\left(2,2^{\prime}\right.$-azinobis-(3-ethylbenzothiazoline-6-sulfonic acid) and Trolox (( \pm )-6-Hydroxy-2,5,7,8-tetramethylchromane-2-carboxylic acid) were obtained from Sigma-Aldrich (Saint Louis, MO, USA), acetonitrile from Merck (Darmstadt, Germany), while methanol, acetone, hydrochloric acid, sodium carbonate and formic acid from POCh (Katowice, Poland).

\section{Buckwheat materials}

The buckwheat leaves (Fagopyrum esculentum) of the following strains (DW15, DWO Karzel, POL8 DW3 GSL1, DWO-Polish origin, as well as Japan 8 and Japan 18Japanese origin) were used for analysis. The plant material was harvested in 2011 in the Department of Cultivation and Production in Palikije (Poland). Leaves were dried in natural condition [at ambient temperature $\left(20-24^{\circ} \mathrm{C}\right)$ in a dark, well-ventilated room]. Natural drying is the most popular method for preservation of herbs and various types of plants $[11,12]$. The samples were crushed in an electric grinder (Tecator Foss, Hillerød, Sweden) and then stored at room temperature in the paper bags until analysis.

\section{Chemical composition}

In samples of leaves, the chemical composition was measured using the AOAC methods [13]: total proteins, according to procedure No. 950.36; crude fat, according to procedure No. 935.38; total dietary fibre, according to procedure No. 991.43; and ash, according to procedure No. 930.05. The digestible carbohydrates content was calculated by the equation: digestible carbohydrates $=100-$ (protein + crude fat + dietary fibre + ash) [14]

\section{Extracts' preparation}

One gram of sample of the buckwheat leaves was weighed in an Erlenmeyer flask. $40 \mathrm{ml}$ of $0.08 \mathrm{~N}$ hydrochloric acid in $80 \%$ methanol was added. The mixtures were extracted at room temperature for $2 \mathrm{~h}$ by shaking (Elpan, water bath shaker type 357, Poland). Then the samples were centrifuged at $1500 \mathrm{rpm}$ for $15 \mathrm{~min}$ (centrifuge type MPW-340, Warsaw, Poland). The supernatants were decanted. The residues were re-extracted with $40 \mathrm{ml}$ of $70 \%$ acetone in the same conditions and centrifuged as mentioned above. Both supernatants were combined and stored at temperature $-20^{\circ} \mathrm{C}$ until analysis.

\section{Infusions' preparation}

$1 \mathrm{~g}$ of buckwheat leaves was weighed in a glass beaker. Leaves were brewed with $100 \mathrm{ml}$ of distilled, deionized water at a temperature of $100{ }^{\circ} \mathrm{C}$ for $5 \mathrm{~min}$. Infusions were filtered using a filter paper into a $100 \mathrm{ml}$ volumetric flask. The volume of the infusions was $100 \mathrm{ml}$ with distilled water and cooled to room temperature.

\section{Determination of total polyphenols}

The content of total polyphenols was estimated by the Folin-Ciocialteu reagent [15]. Methanolic-acetone extracts or infusions were diluted to obtain the ratio of extracts or infusions to distilled water 1:20. The reaction mixtures were prepared by mixing $5 \mathrm{ml}$ of diluted extract, $0.5 \mathrm{ml}$ of the Folin-Ciocalteu reagent and $0.25 \mathrm{ml}$ of $25 \%$ sodium carbonate. The samples were left for $20 \mathrm{~min}$. The absorbance at $760 \mathrm{~nm}$ was measured using a spectrophotometer (UV1800, RayLeigh, Beijing Beifen-Ruili Analytical Instrument Co., Ltd., Beijing, China). Results were expressed as chlorogenic acid equivalents (CGA) in mg CGA per $100 \mathrm{~g}$ of sample.

\section{Determination of antioxidant activity}

Extracts/infusions were also used to determine (spectrometrically) antioxidant activity which was determined by 
two experimental methods: ABTS ${ }^{+}\left(2,2^{\prime}\right.$-azino-bis(3-ethylbenzthiazoline-6-sulfonic acid)) and FRAP (ferric-reducing antioxidant power) assays.

\section{ABTS method}

The determination of antioxidant activity using the free radicals $\mathrm{ABTS}^{+}$was estimated as previously reported by Re et al. [16]. This method involved colorimetric determination of the amount of the colored solution of ABTS ${ }^{+}$ which was reduced by the antioxidants present in the analyzed product.

\section{FRAP method}

The FRAP assay was done according to Benzie and Strain [17]. The assay was based on the reducing power of antioxidant which reduces the ferric ion $\left(\mathrm{Fe}^{3+}\right)$ to the ferrous ion $\left(\mathrm{Fe}^{2+}\right)$. The antioxidant activity was estimated by using the increase in absorbance caused by the generated ferrous ions.

The absorbance of the samples was measured at $734 \mathrm{~nm}$ in $\mathrm{ABTS}^{+}$method as well as at $593 \mathrm{~nm}$ in FRAP method using the spectrophotometer (UV-1800, RayLeigh, Beijing Beifen-Ruili Analytical Instrument Co., Ltd., Beijing, China). Values obtained for each sample (in $\mathrm{ABTS}^{+}$ and FRAP method) were compared to the concentration-response curve of the standard Trolox solution and expressed as micromoles of Trolox equivalent per gram of dry weight (TEAC).

\section{Chromatographic analysis: LC-MS/MS conditions}

An Applied Biosystems/MDS Sciex (Concord, Ontario, Canada) API 2000 triple quadrupole mass spectrometer with an electrospray ionization interface was used. The Agilent 1100 (Agilent Technologies, Waldbrom, Germany) LC system was consisted of the following components: a pump in a gradient mode and an autosampler with a $100 \mu \mathrm{l}$ injection loop.

The chromatographic separation was performed in the gradient mode with a Thermo Scientific BDS HYPERSIL C18 column $100 \times 3 \mathrm{~mm}$ I.D., $3 \mu \mathrm{m}$ particle size (Thermo Scientific, Waltham, MA, USA). The advance column, with a precolumn $(10 \times 3 \mathrm{~mm}$ I.D., $3 \mu \mathrm{m}$ particle size $)$ was maintained at $25{ }^{\circ} \mathrm{C}$ and a mobile phase flow rate was $0.5 \mathrm{ml} /$ min. The optimized mobile phase solvents were: $0.02 \mathrm{M}$ formic acid in water (phase A) and $0.02 \mathrm{M}$ formic acid in acetonitrile (phase B). The gradient started initially at $2 \%$ A in $5 \mathrm{~min}$, it increased linearly to $6 \%$, for $5 \mathrm{~min}$ to $10 \%$, next for $5 \mathrm{~min}$ to $17 \%$, next $5 \mathrm{~min}$ to $36 \%$, next $5 \mathrm{~min}$ to $38 \%$, next $5 \mathrm{~min}$ to $60 \%$, next $5 \mathrm{~min}$ decreased to $40 \%$ and next 5 min increased to $100 \%$, next 2 min decreased to $2 \%$ where it maintained for the next 8 min to stabilize the baseline. The sample temperature was maintained at $4{ }^{\circ} \mathrm{C}$ in the autosampler prior to analysis. Quantification of the analysis was performed using the tandem electrospray MS in a negative mode $\left(\mathrm{ESI}^{-}\right)$. The source parameters were optimized to maximize precursor ion production by direct infusion of the standard solutions (at concentration of $1 \mu \mathrm{g} / \mathrm{ml}$ and the flow rate of $10 \mu \mathrm{l} / \mathrm{min}$ ) into the MS using a single MS monitoring. MS/MS analysis allowed for recording of product ion spectra, monitoring each precursor $\left[\mathrm{M}-\mathrm{H}^{+}\right]^{+}$ion. The mass spectrometer operated with a dwell time of $200 \mathrm{~ms}$. The multiple reaction monitoring (MRM) mode of the dominant product ion for each compound was performed using the optimal conditions. The ion source parameters were as follows: ion spray voltage (IS): $-4200 \mathrm{~V}$; nebulizer gas (gas 1): $30 \mathrm{psi}$; turbo gas (gas 2): $10 \mathrm{psi}$; temperature of the heated nebulizer (TEM): $350{ }^{\circ} \mathrm{C}$; curtain gas (CUR): 20 psi. The ion path parameters obtained following individual compounds optimization are presented in Table 1. These parameters include: decluttering potential (DP), focusing potential (FP), collision energy (CE), collision cell exit potential (CXP). Comparison of precursor/product ion pair $\mathrm{m} / \mathrm{z}$ values and $\mathrm{LC}$ retention times with standards served to confirm the identification of studied compounds in the investigated samples is presented in Table 1. Data acquisition and processing were accomplished using the Applied Biosystems Analyst version 1.4.2 software (Foster City, CA, USA).

\section{Statistical analysis}

Results were expressed as the means \pm standard deviation (SD). Differences between samples were analyzed using Statistica v.10.0 software (Tulsa, OK, USA). Duncan's multiple range test was used for testing the differences. $P$ values $<0.05$ were regarded as significant. Correlations between the antioxidant activity and content of total polyphenols were examined using Pearson's correlation. $P$ values $<0.05$ were regarded as significant.

\section{Results}

\section{Chemical composition}

A statistically significant effect of strain on the content of ash, protein, crude fat and digestible carbohydrates in the leaves of buckwheat was observed (Table 2). The highest ash content was in the strain DW15 and the lowest was in the strain DWO as compared to other strains. The content of protein was significantly lower in strain DW15 and Japan 8 as compared to the other assessed strains. The buckwheat leaves of strain POL8 DW3 GSL1 were characterized by 
significantly the highest content of crude fat. However, strain Japan 18 contained the lowest amount of this compound as compared to the others. The highest digestible carbohydrates content was in the strains Japan 18, DWO and Japan 8 in comparison to other strains. The content of dietary fibre was significantly highest in the strain DW15 in comparison to strain DWO (Table 2).
Total polyphenolic compounds' content and antioxidant activity

A statistically significant effect of strain on the content of total polyphenols in the leaves of buckwheat was found (Table 3). Among the extracts, the amount of total polyphenols was significantly highest in the strains Japan 8 and
Table 1 The ion path parameters obtained following the individual compound's optimization

\begin{tabular}{|c|c|c|c|c|c|c|c|c|}
\hline \multirow[t]{2}{*}{ Compound } & \multirow{2}{*}{$\begin{array}{l}\text { Molecular } \\
\text { mass }(\mathrm{g} / \mathrm{mol}) \\
{[\mathrm{M}]}\end{array}$} & \multicolumn{2}{|l|}{$\mathrm{m} / \mathrm{z}$} & \multirow{2}{*}{$\begin{array}{l}\text { Retention } \\
\text { time (min) }\end{array}$} & \multirow[t]{2}{*}{ DP } & \multirow[t]{2}{*}{ FP } & \multirow[t]{2}{*}{$\mathrm{CE}$} & \multirow[t]{2}{*}{ CXP } \\
\hline & & {$\left[\mathrm{M}-\mathrm{H}^{+}\right]^{-}$} & MRM & & & & & \\
\hline 3,5-dCQA & 516.45 & 514.40 & 352.80 & 22.36 & -70 & -100 & -25 & -10 \\
\hline Ferulic acid & 194.18 & 192.80 & 134.00 & 20.70 & -36 & -250 & -10 & -8 \\
\hline Sinapinic acid & 224.21 & 222.70 & 207.80 & 20.88 & -31 & -160 & -12 & -15 \\
\hline$p$-coumaric acid & 164.16 & 162.80 & 119.10 & 19.81 & -31 & -320 & -9 & -22 \\
\hline Hesperidin & 610.56 & 609.14 & 163.80 & 24.36 & -86 & -50 & -15 & -6 \\
\hline Isorhamnetin & 316.26 & 314.70 & 300.00 & 24.80 & -91 & -340 & -16 & -10 \\
\hline Catechin & 290.27 & 289.27 & a & 15.15 & -20 & -200 & -15 & -15 \\
\hline Rutin & 610.52 & 609.14 & 301.00 & 20.64 & -20 & -200 & -29 & -15 \\
\hline Quercetin & 302.24 & 301.03 & 178.90 & 24.30 & -20 & -200 & -15 & -15 \\
\hline
\end{tabular}

$M R M$ multiple reaction monitoring, $D P$ decluttering potential, $F P$ focusing potential, $C E$ collision energy, $C X P$ collision cell exit potential, 3,5-dCQA 3,5-diCaffeoylquinic acid, $a$ it has not been made fragmentation

Table 2 Basic composition of individual strains of buckwheat leaves (g/100 g DW)

\begin{tabular}{llllll}
\hline Strain & Ash & Protein & Crude fat & Digestible carbohydrates & Dietary fibre \\
\hline DW15 & $19.11 \pm 0.62 \mathrm{~d}$ & $16.81 \pm 0.59 \mathrm{a}$ & $1.58 \pm 0.05 \mathrm{~b}$ & $23.62 \pm 1.69 \mathrm{a}$ & $38.88 \pm 0.37 \mathrm{~b}$ \\
DWO Karzel & $16.55 \pm 0.12 \mathrm{c}$ & $18.11 \pm 0.12 \mathrm{~b}$ & $1.68 \pm 0.05 \mathrm{~b}$ & $26.62 \pm 1.01 \mathrm{ab}$ & $37.68 \pm 0.09 \mathrm{~b}$ \\
POL8 DW3 GSL1 & $17.49 \pm 0.54 \mathrm{c}$ & $17.74 \pm 0.03 \mathrm{~b}$ & $2.40 \pm 0.15 \mathrm{~d}$ & $25.16 \pm 0.15 \mathrm{a}$ & $37.21 \pm 0.19 \mathrm{ab}$ \\
DWO & $12.89 \pm 0.54 \mathrm{a}$ & $18.39 \pm 0.54 \mathrm{~b}$ & $2.08 \pm 0.09 \mathrm{c}$ & $30.64 \pm 1.17 \mathrm{c}$ & $36.01 \pm 0.00 \mathrm{a}$ \\
Japan 8 & $14.56 \pm 0.14 \mathrm{~b}$ & $16.16 \pm 0.18 \mathrm{a}$ & $1.71 \pm 0.08 \mathrm{~b}$ & $30.52 \pm 0.86 \mathrm{c}$ & $37.05 \pm 0.58 \mathrm{ab}$ \\
Japan 18 & $14.22 \pm 0.98 \mathrm{~b}$ & $17.91 \pm 0.30 \mathrm{~b}$ & $1.07 \pm 0.04 \mathrm{a}$ & $29.77 \pm 2.01 \mathrm{bc}$ & $37.03 \pm 0.97 \mathrm{ab}$ \\
\hline
\end{tabular}

Results are expressed as mean \pm SD. Statistically significant effect of strain $(p<0.05)$ on the content of compounds are indicated by letter code a-d

$D W$ dry weight

Table 3 Bioactive compounds of individual strains of buckwheat leaves

\begin{tabular}{|c|c|c|c|c|c|c|}
\hline \multirow[t]{2}{*}{ Strain } & \multicolumn{2}{|c|}{ Total polyphenols (mg/100 g DW) } & \multicolumn{2}{|c|}{$\mathrm{ABTS}^{+}(\mu \mathrm{mol}$ Trolox/g DW) } & \multicolumn{2}{|c|}{ FRAP $(\mu$ mol Trolox/g DW $)$} \\
\hline & Extracts & Infusions & Extracts & Infusions & Extracts & Infusions \\
\hline DW15 & $1754.57 \pm 33.36 \mathrm{bc}$ & $1177.73 \pm 27.39 \mathrm{ab}$ & $725.00 \pm 12.73 \mathrm{~d}$ & $388.76 \pm 17.42 b$ & $959.75 \pm 26.84 b c$ & $537.41 \pm 18.88 b$ \\
\hline DWO Karzel & $1953.44 \pm 10.03 \mathrm{e}$ & $1483.06 \pm 70.82 \mathrm{c}$ & $826.27 \pm 25.52 \mathrm{f}$ & $448.98 \pm 13.24 \mathrm{c}$ & $1047.18 \pm 18.70 \mathrm{c}$ & $645.46 \pm 32.93 \mathrm{c}$ \\
\hline POL8 DW3 GSL1 & $1408.21 \pm 47.99 \mathrm{a}$ & $1173.51 \pm 12.35 \mathrm{ab}$ & $518.43 \pm 31.57 \mathrm{a}$ & $392.85 \pm 3.93 b$ & $795.04 \pm 30.49 a$ & $519.08 \pm 9.47 \mathrm{ab}$ \\
\hline DWO & $1654.72 \pm 3.28 b$ & $1141.06 \pm 18.91 \mathrm{a}$ & $610.25 \pm 33.40 b$ & $306.50 \pm 20.04 a$ & $833.42 \pm 26.44 \mathrm{ab}$ & $482.99 \pm 4.81 \mathrm{a}$ \\
\hline Japan 8 & $1862.73 \pm 32.23 \mathrm{de}$ & $1536.35 \pm 23.06 \mathrm{c}$ & $803.33 \pm 30.74 \mathrm{e}$ & $457.44 \pm 10.66 \mathrm{c}$ & $1002.13 \pm 11.08 \mathrm{c}$ & $707.45 \pm 4.76 \mathrm{~d}$ \\
\hline Japan 18 & $1837.95 \pm 22.81 \mathrm{~cd}$ & $1275.82 \pm 35.61 b$ & $695.10 \pm 14.50 \mathrm{c}$ & $387.51 \pm 13.32 b$ & $835.25 \pm 15.29 \mathrm{ab}$ & $479.48 \pm 14.33 \mathrm{a}$ \\
\hline
\end{tabular}

$D W$ dry weight

Results are expressed as mean \pm SD. Statistically significant effect of cultivar strain $(p<0.05)$ on the content of compounds are indicated by letter code $\mathrm{a}-\mathrm{f}$ 
DWO Karzel in comparison to other strains. Among the infusions, the highest content of polyphenols also was in the strains Japan 8 and DWO Karzel as compared to other strains. Statistically significant effect of strain on the antioxidant activity in the buckwheat leaves was found (Table 3). The results of $\mathrm{ABTS}^{+}$and FRAP methods indicated that among the extracts and infusions, the strains Japan 8 and DWO Karzel were exhibited by significantly the highest antioxidant activity in comparison to other strains. Among the extracts, the antioxidant activity was significantly the lowest in the strain POL8 DW3 GSL1 as well as among the infusions-DWO, which was confirmed by both $\mathrm{ABTS}^{+}$and FRAP assays.

\section{Polyphenolic compounds' profile}

The DAD (diode array detector) chromatogram of the reference substances dissolved in methanol is shown in Fig. 1. The DAD chromatogram analysis, TIC (total ion current) and XIC (extracted-ion chromatogram) analyses for the methanolic-acetone extracts and infusions of strain POL8 DW3 GSL1 were presented in Figs. 2, 3 and 4. Presence of phenolic acids (3,5-diCQA, ferulic acid, sinapinic acid, $p$-coumaric acid), flavanones (hesperidin), flavonoids (isorhamnetin) as well as flavanols (catechin) and flavonols (rutin, quercetin) in the tested extracts and infusions, was confirmed. Based on the standard substances, retention time and surface area of the obtained signals, the content of individual polyphenols was measured (Table 4). Among extracts and infusions the largest amount of the marked compounds was identified in the strains POL8 DW3 GSL1,
Japan 18 and DWO Karzel. Among extracts the lowest amount of polyphenols was obtained in the strain DW15 as well as among infusions-in strain Japan 8. The analysis of the polyphenols contained showed that the largest quantity of 3,5-diCQA was found in strain POL8 DW3 GSL1 in both the extract and infusion. On the other hand, the strains DW15, DWO and Japan 8 contained the lowest quantity of this acid in both the extracts and infusions. The marked phenolic acids, such as ferulic acid, were found in the tested material. The highest concentration of the ferulic acid, in both the extract and infusion, was obtained for the strain POL8 DW3 GSL1. The lowest quantities of ferulic acid were found in the extract and infusion of the strains DW 15 and Japan 8. Among extracts the highest content of sinapinic acid was analyzed in the strain DWO, while among infusions-in the strain DWO Karzel. The smallest quantities of sinapinic acid were found in the extracts of the strain POL8 DW3 GSL1 as well as in the infusion of the strain Japan 8. The highest concentration of $p$-coumaric acid was measured in the extract of strain DWO and in the infusion of strain Japan 8. The lowest content of this acid was obtained in the extract of strain DW 15 and in the infusion of strain Japan 18. Among extracts the highest concentration of hesperidin was found in strain DWO, while the lowest-in strain DW15. Among infusions the largest amounts of this compound was measured in strains Japan 8, POL8 DW3 GSL1, DWO and DWO Karzel, as well as the smallest amount of hesperidin was contained in the strains DW 15 and Japan 8. The largest quantity of isorhamnetin was found in strain Japan 18, while the smallest—in the strain DWO, in both the extracts
Fig. 1 Chromatogram DAD of the reference substances dissolved in methanol

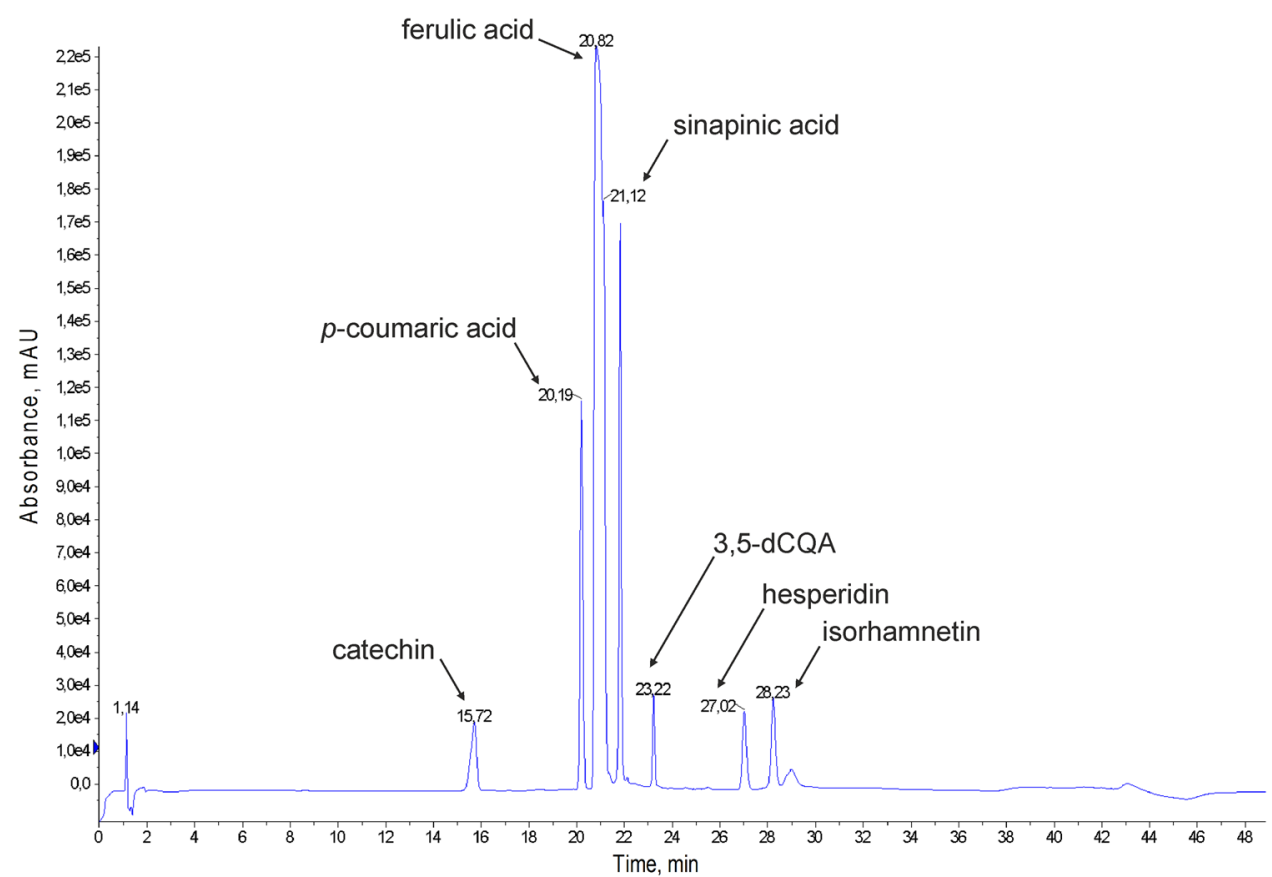


Fig. 2 Examples of chromatogram DAD for a POL8 DW3 GSL1 sample: extract (a), infusion (b)
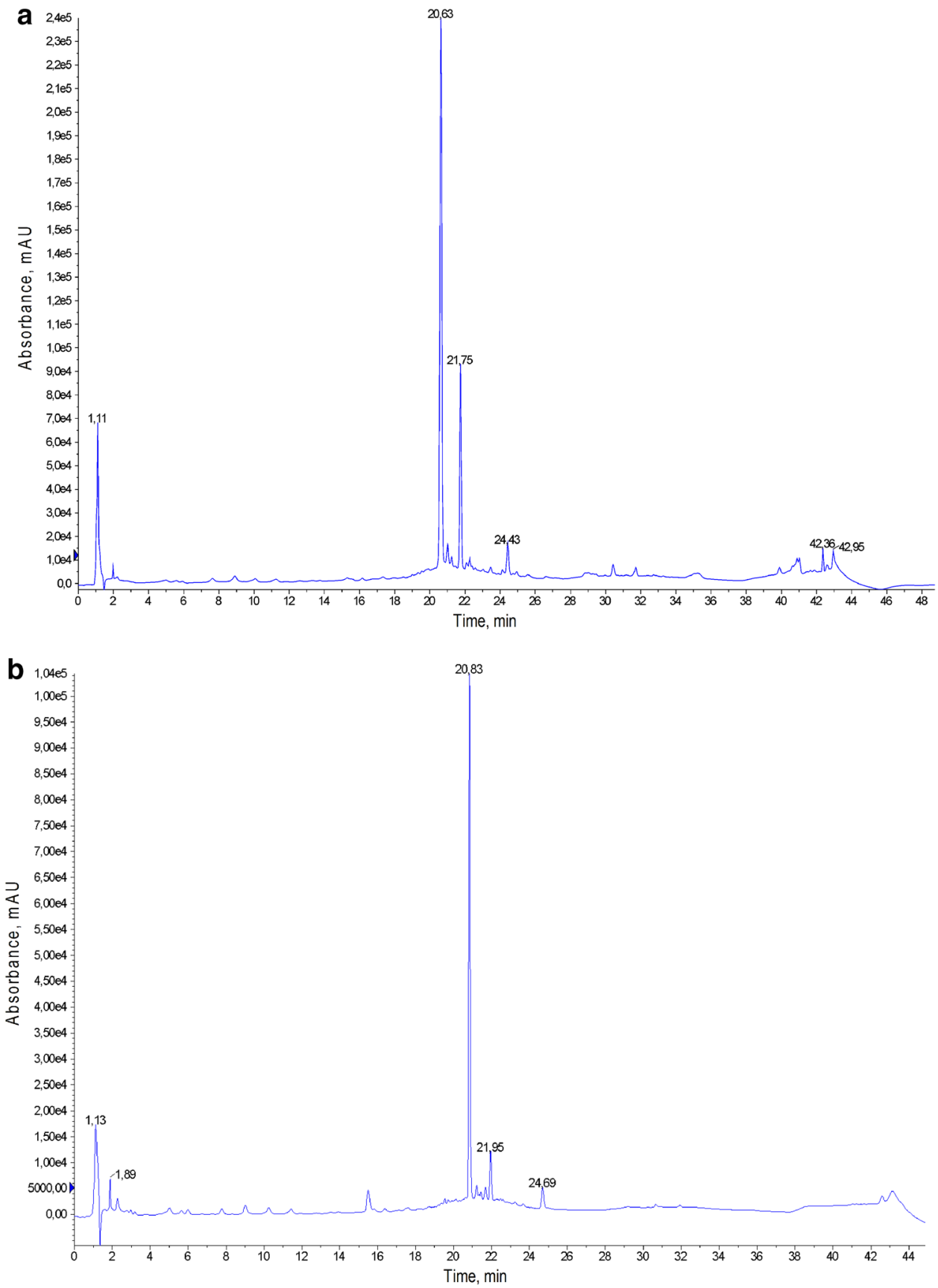

and infusions. The highest content of catechin was found in the extracts and infusions of strains DW15 and DWO Karzel. In the extract, the lowest amount of this compound was measured in strain Japan 18, while in the infusion-in strain Japan 8. Based on the parent ion $\mathrm{m} / \mathrm{z}$, daughter ions, and retention time, presence of rutin and quercetin was determined. In both the extracts and infusions, the highest content of rutin was in strain Japan 8 and the lowest-in strain POL8 DW3 GSL1. Among the extracts, the largest quantity of quercetin was measured in the strain Japan 18, however among infusions-in strain DWO. The smallest content of this polyphenol was found in strain POL8 DW3 GSL1, in both the extracts and infusions.

\section{Discussion}

Based on the results of this research it was found that buckwheat leaves can be recognized as the rich source of bioactive compounds. In examined strains the average content of ash was 16.58/100 g. The lower level of ash was observed by other authors. Lahanov et al. [18] reported that the ash 

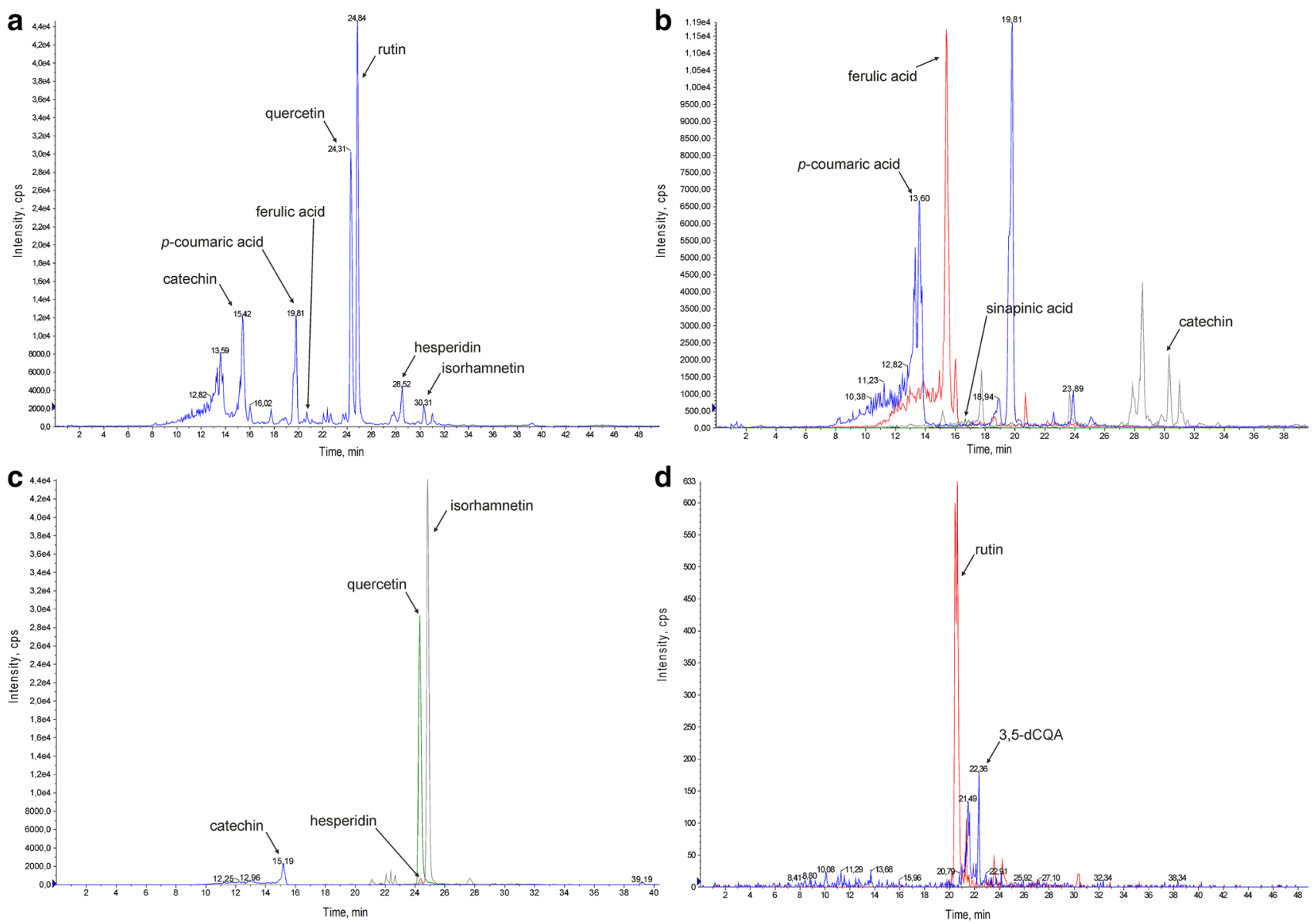

Fig. 3 Examples of chromatograms for a POL8 DW3 GSL1 sample extract: chromatogram TIC (a), chromatogram XIC obtained for the maximum absorbing wavelength at each time point $(\mathbf{b}-\mathbf{d})$

content in leaves of cultivar Bogatyr, which came from Russia, was $13.4 / 100 \mathrm{~g}$. The similar amount was characterized by a cultivar Shinanonatsusoba from Japan. In the cultivar M-822 (from China) and Mankan Royal (from Canada) ash content was 14.2/100 g. Dogra [19] reported that content of ash in leaves of buckwheat in the different samples varied significantly from $10.5 / 100 \mathrm{~g}$ (for genotype S-B-201) to 15.4/100 g (for genotype VHC-27). According to Piątkowska et al. [20], who examined the Polish cultivars, the content of ash in buckwheat leaves was in the range $12.3 / 100 \mathrm{~g}$ (for cultivar Panda) to 14.7/100 g (for cultivar Kora). Additionally, leaves had higher concentration of ash in comparison to the seeds. Based on literature data, in seeds average concentration of ash was in the range 1.72/100-4.64/100 g [21,22]. The average protein content in studied leaves of buckwheat was $17.33 / 100 \mathrm{~g}$. The higher content of this compound was found by Lahanov et al. [18] and it was 24.3/100 g. Similar results were reported by Dogra [19], who studied buckwheat from India. He showed that the content of protein differed significantly from 22.4/100 g (for genotype OC-2) to $30.4 / 100 \mathrm{~g}$ (for genotype S-B-212). Piątkowska et al. [20] reported the similar content of this compound in Polish cultivars (24.3-27.2/100 g). Leaves in comparison to dehulled seeds contained similar amount of protein [3,9]. The content of crude fat in buckwheat leaves, which was determined in our study, was on average 1.68/100 g. Dogra [19] showed the higher content of this compound (1.8-3.7/100 g). Lower amount of fat in the buckwheat leaves was shown by Piątkowska et al. [20]. These authors reported that, in the cultivar Kora, the content of this compound was $0.9 / 100 \mathrm{~g}$, in the cultivars Panda and Red Corolla-1.1/100 g. Leaves contained similar amount of crude fat in comparison to the dehulled seeds and whole seeds. Kowalewski et al. [22] showed that concentration of fat in dehulled seeds was $1.73 \mathrm{~g} / 100 \mathrm{~g}$. Krkoškova and Mrázová [23] reported that whole seeds of buckwheat contained 2.30/100 g of fat. In our study, the average content of digestible carbohydrates was 26.83/100 g. Dogra [19] reported the content of these compounds in leaves in the range of $34.8-42.4 / 100 \mathrm{~g}$. The average content dietary fibre in assessed strains was in the 

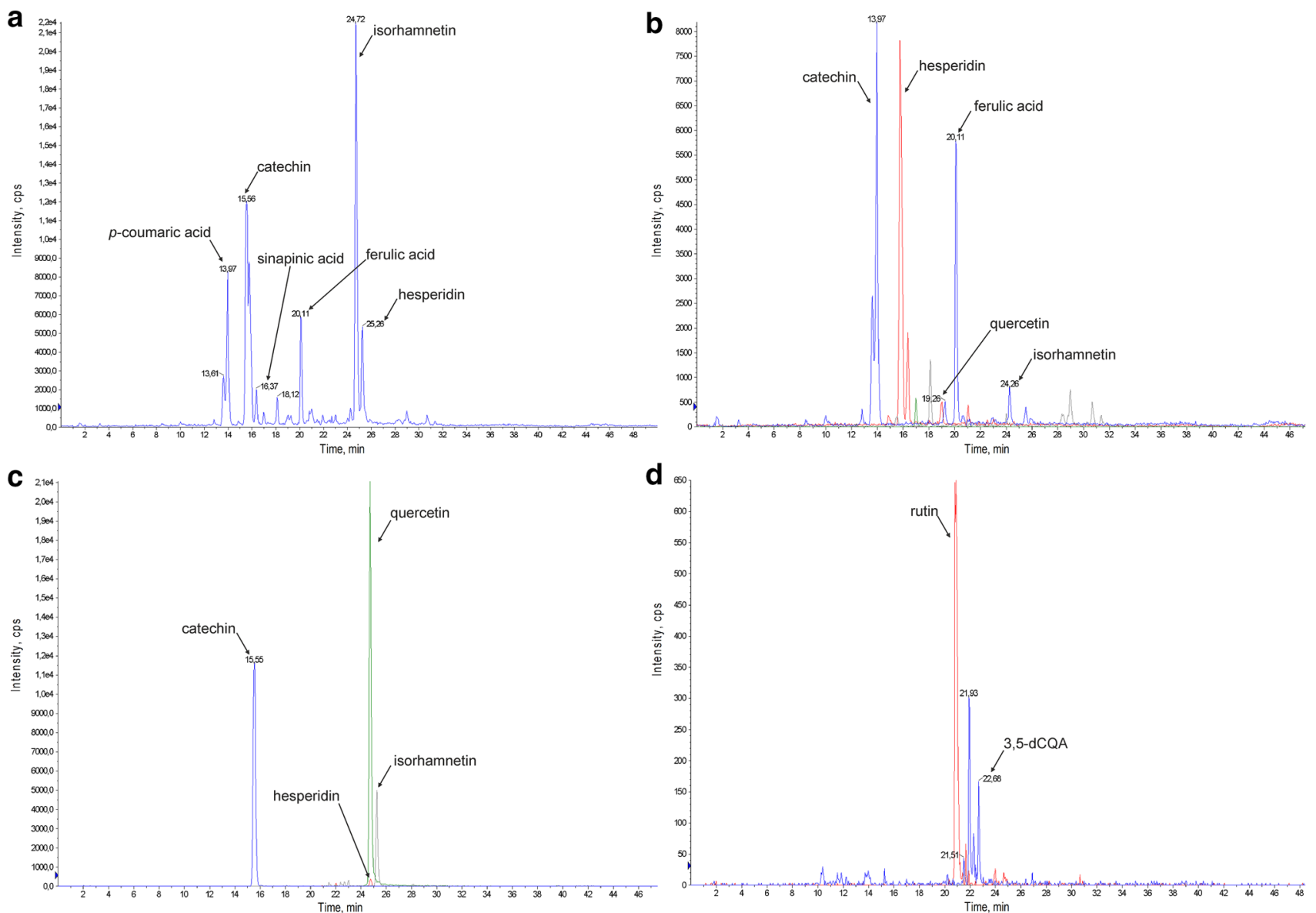

Fig. 4 Examples of chromatograms for a POL8 DW3 GSL1 sample infusion: chromatogram TIC (a), chromatogram XIC obtained for the maximum absorbing wavelength at each time point $(\mathbf{b}-\mathbf{d})$

range 36.01-39.22/100 g. The results obtained in this study are similar to the data published by Dogra [19]. The lower content of fibre (18.4/100 g) was found in leaves of buckwheat by Leiber et al. [24]. Leaves contained higher amount of dietary fibre in comparison to the seeds (dehulled and whole seeds). It has been reported that in the dehulled and whole seeds the concentration of dietary fibre was 3.70/100 and 27.38/100 g, respectively [22]. Differentiation of chemical composition could be caused by various conditions of cultivation and different resistance of individual strains to weather conditions.

In the extracts from the tested buckwheat leaves, the content of total polyphenols varied from 1408.21 to $1953.44 \mathrm{mg}$ of CGA/100 g depending on the strain. Among infusions, the amount of these compounds was lower and was in the range 1141.06-1536.35 $\mathrm{mg}$ of CGA/100 $\mathrm{g}$ depending on the studied strain. The differences in the content of total polyphenols observed in the examined leaves of buckwheat could result from the cultivation of factors: agrotechnical procedures (in cultivation and harvesting), ripeness of the material, harvesting time, storage conditions or effect of genetic factors. Piątkowska et al. [20] reported lower content of polyphenols compounds in the extracts and infusions of buckwheat leaves in different cultivars (Kora, Panda and Red Corolla). These amounts were lower than the obtained in our research. Dogra [19] analyzed the content of total polyphenols in the extracts of the buckwheat leaves in five cultivars and obtained similar results to this determined in our study for one cultivar (1800 mg of GEA/100 g) and the higher content of polyphenols for the other (2100-3200 mg of GEA/100 g). Also other authors reported the higher amounts of these compounds. Holasova et al. [25] showed the content of total polyphenols in leaves of buckwheat, which was $3951.4 \mathrm{mg}$ of GEA/100 g. Leiber et al. [24] also demonstrated higher content of these compounds $(6300 \mathrm{mg}$ of GEA/100 g). The lower content of phenolic compounds in the extracts from the buckwheat leaves $(580 \mathrm{mg} / 100 \mathrm{~g})$ was found by Dogra [19].

The tested extracts were characterized by higher antioxidant activity than infusions, which was confirmed by both $\mathrm{ABTS}^{+}$and FRAP assays. These results showed that the organic solvents (e.g. methanol, acetone) could be better 
solvents for the antioxidant compounds than water. Moreover, some antioxidant compounds could be sensitive to high temperature, which could cause their degradation during the preparation of the infusions. Piątkowska et al. [20] also determined a higher antioxidant activity in extracts than in infusions from the leaves of buckwheat in $\mathrm{ABTS}^{+}$test. It can confirm these conclusions. Both in the extracts and infusions, the cultivars strains DWO Karzel and Japan 8 had the highest content of phenolic compounds, as well as the highest antioxidant activity (determined by $\mathrm{ABTS}^{+}$and FRAP methods). Statistically significant correlation between the content of total polyphenols and the antioxidant activity measured $\mathrm{ABTS}^{+}$and FRAP tests in studied strains was found ( $r=0.9447$ and $r=0.9225$ respectively). These data indicate that the polyphenols could be the main compounds in the leaves of buckwheat, which are responsible for antioxidant activity. Based on the available literature, leaves had the higher concentration of polyphenolic compounds as well as antioxidant activity in comparison to the seeds. The average concentration of polyphenolic compounds in seeds was in the range $245.40 \mathrm{mg} / 100 \mathrm{~g}-339.34 \mathrm{mg} / 100 \mathrm{~g}[21,26]$.

We have found that the extract as well as the infusion of the strain POL8 DW3 GSL1 was the richest source of ferulic acid. This polyphenolic compound has strong antioxidant activity which was confirmed in in vivo studies [27-29]. Li et al. [30], who studied the ethanolic extract, have reported that leaves of common buckwheat contained 2.07/100 mg DW of ferulic acid. According to the best knowledge of authors there was no information concerning the identification of ferulic acid as well as sinapinic acid and $p$-coumaric acid in infusions prepared from the buckwheat leaves.

We have also found that extracts and infusions contained flavanones (hesperidin), flavonoids (isorhamnetin), flavanols (catechin) as well as flavonols (rutin, quercetin). Li et al. [30] showed that leaves of buckwheat contained rutin, but they did not identified quercetin. Also Zielińska et al. [31] reported that leaves of common and tartary buckwheat were a good source of rutin. The results of Kreft et al. [32] revealed that buckwheat beer and vinegar contained a negligible amount of this polyphenolic compound. Nakamura et al. [33] found that the lactic fermentation of buckwheat sprouts decreased the level of quercetin. Buckwheat seeds generally had similar polyphenolic compounds like leaves, but the content of them may be different [21, 26, 31]. In our previous studies we identified following phenolic compounds: rutin, vitexin epicatechin, catechin, quercitin, caffeic acid hexose in whole seeds of different Polish cultivars (Panda, Kora and other) [21]. Klepacka et al. [26] reported that dehulled seeds of Kora, Panda and Luba contained $p$-coumaric, syringic, ferulic and vanillic acid. Similar polyphenolic compounds were identified by Kiprovski et al. [2] in buckwheat seeds and by Verardo et al. [34] in buckwheat flour. 


\section{Conclusions}

The leaves of buckwheat are a source of bioactive compounds and they have a high ash and protein content. A statistically significant effect of strain on the content of individual components was observed. The strains DWO Karzel and DW15 were characterized by one of the highest contents of polyphenols, dietary fibre, protein, ash and antioxidant activity. The extracts contained more polyphenols and were characterized by higher antioxidant activity than infusions. We have found that both extracts and infusions are the richest in ferulic acid. Leaves of buckwheat, due to the high content of polyphenols, can favorably affect the human body, and thus they can be used in the prevention and treatment of chronic non-communicable diseases. Consequently, buckwheat leaves can be used in the production of drinks or as food additives, being a source of phytochemicals. There is a need for further research of these strains to be used for the production of novel functional foods.

Acknowledgements The study was financed by Ministry of Science and Higher Education of the Republic of Poland.

\section{Compliance with ethical standards}

Conflict of interest The authors declare that they have no conflict of interest.

Compliance with ethics requirements This article does not contain any studies with human or animal subjects.

Open Access This article is distributed under the terms of the Creative Commons Attribution 4.0 International License (http://creativecommons.org/licenses/by/4.0/), which permits unrestricted use, distribution, and reproduction in any medium, provided you give appropriate credit to the original author(s) and the source, provide a link to the Creative Commons license, and indicate if changes were made.

\section{References}

1. Bonafaccia G, Marocchini M, Kreft I (2003) Composition and technological properties of the flour and bran from common and tartary buckwheat. Food Chem 80:9-15

2. Kiprovski B, Mikulic-Petkovsek M, Slatnar A et al (2015) Comparison of phenolic profiles and antioxidant properties of European Fagopyrum esculentum cultivars. Food Chem 185:41-47

3. Gasiorowski H (2008) Buckwheat (part 2). Nutritional and chemical characteristics. Przegląd Zbożowo-Młynarski 52:14-17

4. Giovannini C, Masella R (2012) Role of polyphenols in cell death control. Nutr Neurosci 15:134-149

5. Borkowska B, Robaszewska A (2012) Use of buckwheat grain in various industry branches. Zesz Nauk Akad Morskiej w Gdyni 73:43-55

6. Quirós-Sauceda AE, Palafox-Carlos H, Sáyago-Ayerdi SG et al (2014) Dietary fiber and phenolic compounds as functional ingredients: interaction and possible effect after ingestion. Food Funct $5: 1063$
7. Gorecka D, Hes M, Szymandera-Buszka K, Dziedzic K (2009) Contents of selected bioactive components in buckwheat groats. Acta Sci Pol Technol Aliment 8:75-83

8. Inglett GE, Chen D, Berhow M, Lee S (2011) Antioxidant activity of commercial buckwheat flours and their free and bound phenolic compositions. Food Chem 125:923-929

9. Stempińska K, Soral-Śmietana M, Zieliński H, Michalska A (2007) Effect of thermal treatment on chemical and antioxidant properties of buckwheat grains. Żywność Nauk Technol Jakość 5:66-76

10. Yang N, Li YM, Zhang K et al (2014) Hypocholesterolemic activity of buckwheat flour is mediated by increasing sterol excretion and down-regulation of intestinal NPC1L1 and ACAT2. J Funct Foods 6:311-318

11. Díaz-Maroto MC, Pérez-Coello MS, Cabezudo MD (2002) Effect of different drying methods on the volatile components of parsley (Petroselinum crispum L.). Eur Food Res Technol 215:227-230

12. Hossain MB, Barry-Ryan C, Martin-Diana AB, Brunton NP (2010) Effect of drying method on the antioxidant capacity of six Lamiaceae herbs. Food Chem 123:85-91

13. Horwitz W, Latimer GW (2005) Official methods of analysis of AOAC International, 18th edn. AOAC International, Gaithersburg

14. Fortuna T, Rożnowski J (2012) Wybrane zagadnienia z chemii żywności: skrypt do ćwiczeń, 2nd edn. Wydawnictwo Uniwersytetu Rolniczego, Kraków

15. Swain T, Hillis WE (1959) The phenolic constituents of Prunus domestica. I.-The quantitative analysis of phenolic constituents. J Sci Food Agric 10:63-68

16. Re R, Pellegrini N, Proteggente A et al (1999) Antioxidant activity applying an improved ABTS radical cation decolorization assay. Free Radic Biol Med 26:1231-1237

17. Benzie I, Strain J (1996) The ferric reducing ability of plasma (FRAP) as a measure of "antioxidant power": the FRAP assay. Anal Biochem 239:70-76

18. Lahanov AP, Muzalevskaja RS, Shelepina NV, Gorkova IV (2004) Biochemical characteristics of some species of genus Fagopyrum Mill. In: Proceedings of the 9th international symposium on buckwheat, Prague, pp 604-611

19. Dogra D (2010) Biochemical evaluation of buck wheat Fagopyrum esculentum Moench genotypes. CSK Himachal Pradesh Krishi Vishvavidyalaya

20. Piątkowska E, Witkowicz R, Janeczko Z et al (2015) Basic chemical composition and antioxidant activity leaves of selected buckwheat's varieties and tartary buckwheat. Fragm Agron 32:92-100

21. Dziadek K, Kopeć A, Pastucha E et al (2016) Basic chemical composition and bioactive compounds content in selected cultivars of buckwheat whole seeds, dehulled seeds and hulls. J Cereal Sci 69:1-8

22. Kowalewski W, Galazka R, Gasiorowska T (2004) The technology of processing of buckwheat for groats. Przegląd ZbożowoMłynarski 6:28-30

23. Krkošková B, Mrázová Z (2005) Prophylactic components of buckwheat. Food Res Int 38:561-568

24. Leiber F, Kunz C, Kreuzer M (2012) Influence of different morphological parts of buckwheat (Fagopyrum esculentum) and its major secondary metabolite rutin on rumen fermentation in vitro. Orig Pap Czech J Anim Sci 57:10-18

25. Holasova M, Fiedlerova V, Smrcinova H et al (2002) Buckwheat-the source of antioxidant activity in functional foods. Food Res Int 35:207-211

26. Klepacka J, Gujska E, Michalak J (2011) Phenolic compounds as cultivar- and variety-distinguishing factors in some plant products. Plant Foods Hum Nutr 66:64-69

27. Kim SP, Kang MY, Nam SH, Friedman M (2012) Dietary rice bran component $\gamma$-oryzanol inhibits tumor growth in tumor-bearing mice. Mol Nutr Food Res 56:935-944 
28. Son MJ, Rico CW, Nam SH, Kang MY (2010) Influence of oryzanol and ferulic acid on the lipid metabolism and antioxidative status in high fat-fed mice. J Clin Biochem Nutr 46:150-156

29. Wang O, Liu J, Cheng Q et al (2015) Effects of ferulic acid and $\gamma$-oryzanol on high-fat and high-fructose diet-induced metabolic syndrome in rats. PLoS One 10:e0118135

30. Li X, Il Park N, Xu H et al (2010) Differential expression of flavonoid biosynthesis genes and accumulation of phenolic compounds in common buckwheat (Fagopyrum esculentum). J Agric Food Chem 58:12176-12181

31. Zielińska D, Turemko M, Kwiatkowski J, Zieliński H (2012) Evaluation of flavonoid contents and antioxidant capacity of the aerial parts of common and tartary buckwheat plants. Molecules $17: 9668-9682$
32. Kreft I, Fabjan N, Yasumoto K (2006) Rutin content in buckwheat (Fagopyrum esculentum Moench) food materials and products. Food Chem 98:508-512

33. Nakamura K, Naramoto K, Koyama M (2013) Blood-pressurelowering effect of fermented buckwheat sprouts in spontaneously hypertensive rats. J Funct Foods 5:406-415

34. Verardo V, Arráez-Román D, Segura-Carretero A et al (2010) Identification of buckwheat phenolic compounds by reverse phase high performance liquid chromatography-electrospray ionizationtime of flight-mass spectrometry (RP-HPLC-ESI-TOF-MS). J Cereal Sci 52:170-176 